\section{Reduced Plant Growth in Tomato Mutants high pigment and dark green Partially Overcome by Gibberellin}

\author{
E. Van Wann ${ }^{1}$ \\ U.S. Department of Agriculture, Agricultural Research Service, South Central \\ Agricultural Research Laboratory, Lane, OK 74555
}

Additional index words. Lycopersicon esculentum, gene action, pleiotropy, growth regulator

Genetic mutants high pigment $(h p)$ and dark green $(d g)$ were first recognized and described in tomato (Lycopersicon esculentum Mill.) because of their effects on chlorophyll content in vegetative parts and carotenoid pigments in the fruit (Kerr, 1960; Konsler, 1973). Both mutants affect several other unrelated characteristics, including enhanced ascorbic acid (vitamin C), increased fruit firmness, brittle stems, and reduced plant growth (Jarret et al., 1984). The two mutants are not allelic (Jarret et al., 1984; Thompson, 1961; Wann et al., 1985), yet their effects on the whole plant are almost identical. The $h p$ and $d g$ genotypes cannot be distinguished from each other based on phenotype alone. The multiple effects of $h p$ and $d g$ have been described as pleiotropy rather than genetic linkages (Jarret et al., 1984).

The effects of $h p$ and $d g$ on fruit quality are considered beneficial. Their practical use, however, has been restricted due to reduced plant growth. Numerous attempts have been made to overcome the growth-retarding effects of $h p$ and $d g$ through conventional breeding and selection procedures. To date, none of the segregating populations have produced recombinant individuals with normal growth.

Jarret et al. (1984) reported that $h p$ and $d g$ decreased stem length, leaf area, and wholeplant fresh and dry weights, but did not affect the number of nodes. The phenotypes relative to plant morphology resemble those described for gibberellin-deficient mutants in tomato (Koornneef et al., 1990). I endeavored to determine whether exogenous gibberellin would overcome the growth-retarding effect of mutants $h p$ and $d g$.

Tomato breeding lines carrying the $h p$ and $d g$ genes were crossed with 'Flora-Dade'. The mutant genotypes were reselected from segre-

Received for publication 15 Aug. 1994. Accepted for publication $26 \mathrm{Dec}$. 1994. The cost of publishing this paper was defrayed in part by the payment of page charges. Under postal regulations, this paper therefore must be hereby marked advertisement solely to indicate this fact.

${ }^{1}$ Research Geneticist. gating progenies and backcrossed twice to 'Flora-Dade', with selection for genotype following each backcross. Inbred mutant lines, designated T4065 $h p$ and T4099 $d g$, were selected for comparison with the recurrent parent for their response to foliar applications of gibberellic acid $\left(\mathrm{GA}_{7}\right)$. Sixteen plants each of T4065 $h p$, T4099 $d g$, and 'Flora-Dade' were grown in a glasshouse in 4-liter pots filled with a commercial potting mix at 20 to $23 \mathrm{C}$ under natural light when the photoperiod was $\approx 12 \mathrm{~h}$. The plants were arranged in a splitplot design in which the main plots were 0 and $5 \mathrm{mg} \mathrm{GA}_{7} /$ liter, and subplots were genotypes. The experiment was replicated eight times. Beginning at the first true-leaf stage, plants in the treated plots were atomized twice weekly with $\mathrm{GA}_{7}$ (Koornneef et al., 1990). Plants in the control plots were atomized with distilled water. Applications of $\mathrm{GA}_{7}$ were continued for 3 weeks (six applications), at which time the plants had initiated the eighth internode. Four days after the final application, all plants were severed at the cotyledonary node, and the length of each succeeding internode was measured. Dry weights of the whole plant were determined. Data were subjected to analysis of variance, and means were separated by Duncan's multiple range test.

Treated plants of T4065 $(h p)$, T4099 $(d g)$, but not of 'Flora-Dade' had longer stems than the controls (Table 1). Although the two mutant genotypes still had shorter stem lengths than 'Flora-Dade' following the $\mathrm{GA}_{7}$ treatments, the magnitude of that difference was greatly reduced compared to nontreated plants. The increase in stem length due to exogenous at the first true-leaf stage. the genotype.
$\mathrm{GA}_{7}$ on 'Flora-Dade' was $11 \%$, while increases on T4065 $h p$ and T4099 $d g$ were $36 \%$ and $43 \%$, respectively. The increases in stem length were evenly distributed over the first six internodes (data not shown). There was a genotype $\times$ treatment interaction for stem length but not for plant dry weight. The differences between treatment means for plant dry weight within genotypes were nonsignificant.

The $\mathrm{GA}_{7}$ treatments at the concentration used in this experiment did not bring the mutant genotypes to equal nontreated 'FloraDade' for either stem length or plant dry weight. We used a relatively low concentration of $\mathrm{GA}_{7}$ because we expected it to elicit a differential response between possible gibberellin-deficient lines and the normal genotype. However, a higher concentration of $\mathrm{GA}_{7}$ likely would have elicited a greater growth response in the mutant genotypes and produced plants more nearly equal in size to those of the control.

The response of $h p$ and $d g$ genotypes to exogenous gibberellic acid beyond that exhibited by the normal genotype ('Flora-Dade') suggests a deficiency in the mutants for gibberellin synthesis, which would account for their dwarfish plant type and brittle stems (Koornneef et al., 1990). Exploiting the benefits of $h p$ and $d g$ seems dependent on developing a scheme for overcoming their detrimental effect on plant growth.

\section{Literature Cited}

Jarret, R.L., H. Sayama, and E.C. Tigchelaar. 1984. Pleiotropic effects associated with the chlorophyll intensifier mutations high pigment and dark green in tomato. J. Amer. Soc. Hort. Sci. 109:873-878.

Kerr, E.A. 1960. High pigment ratios. Rpt. Tomato Genet. Coop. 10:18-19.

Konsler, T.R. 1973. Three mutants appearing in 'Manapal' tomato. HortScience 8:331-333.

Koornneef, M., T.D.G. Bosma, C.J. Hanhart, J.H. van der Veen, and J.A.D. Zeevaart. 1990. The isolation and characterization of gibberellindeficient mutants in tomato. Theor. Appl. Genet. 80:852-857.

Thompson, A.E. 1961. A comparison of fruit quality constituents of normal and high pigment tomatoes. Proc. Amer. Soc. Hort. Sci. 78:464-473.

Wann, E.V., E.L. Jourdain, R. Pressey, and B.G. Lyon. 1985. Effect of mutant genotypes $h p o g^{c}$ and $d g o^{c}$ on tomato fruit quality. J. Amer. Soc. Hort. Sci. 110:212-215.

Table 1. Stem length and plant dry weight of high pigment $(h p)$ and dark green $(d g)$ and normal tomato plants, with and without the application of exogenous gibberellic acid $\left(\mathrm{GA}_{7}\right)^{\mathrm{z}}$

\begin{tabular}{lccccc}
\hline \hline & \multicolumn{2}{c}{ Stem length $(\mathrm{mm})$} & & \multicolumn{2}{c}{ Plant dry wt $(\mathrm{g})$} \\
\cline { 2 - 3 } Genotype & Control & $\mathrm{GA}_{7}$ & & Control & $\mathrm{GA}_{7}$ \\
\hline Flora-Dade (normal) & $251 \mathrm{a}^{\mathrm{y}}$ & $278 \mathrm{a}$ & & $4.47 \mathrm{a}$ & $4.54 \mathrm{a}$ \\
T4065 $(h p)$ & $163 \mathrm{~b}$ & $222 \mathrm{~b}^{*}$ & & $3.29 \mathrm{~b}$ & $3.53 \mathrm{~b}$ \\
T4099 $(d g)$ & $161 \mathrm{~b}$ & $230 \mathrm{~b}^{*}$ & & $2.87 \mathrm{~b}$ & $3.54 \mathrm{~b}$ \\
\hline
\end{tabular}

${ }^{2}$ Gibberellic acid $\left(\mathrm{GA}_{7}\right.$ at $\left.5 \mathrm{mg} \cdot \mathrm{liter}^{-1}\right)$ was atomized on plant foliage twice weekly for 3 weeks, beginning

'Mean separation within columns by Duncan's multiple range test, $P \leq 0.05$.

"Mean followed by * indicates that treated plants are significantly different $(P \leq 0.05)$ from nontreated within 